\title{
Article
}

\section{Argument, Deliberation, Dialectic and the Nature of the Political: A CDA Perspective}

Fairclough, Isabela and Fairclough, Norman

Available at http://clok.uclan.ac.uk/8940/

Fairclough, Isabela ORCID: 0000-0001-6718-2636 and Fairclough, Norman (2013) Argument, Deliberation, Dialectic and the Nature of the Political: A CDA Perspective. Political Studies Review, 11 (3). pp. 336-344. ISSN 14789299

It is advisable to refer to the publisher's version if you intend to cite from the work. http://dx.doi.org/10.1111/1478-9302.12025

For more information about UCLan's research in this area go to

http://www.uclan.ac.uk/researchgroups/ and search for <name of research Group>.

For information about Research generally at UCLan please go to http://www.uclan.ac.uk/research/

All outputs in CLoK are protected by Intellectual Property Rights law, including Copyright law. Copyright, IPR and Moral Rights for the works on this site are retained by the individual authors and/or other copyright owners. Terms and conditions for use of this material are defined in the policies page. 
Isabela Fairclough (University of Central Lancashire) and Norman Fairclough (University of Lancaster)

Argument, deliberation, dialectic and the nature of the political. A CDA perspective ${ }^{1}$

We are grateful to Alan Finlayson and Colin Hay for these challenging responses to our book ${ }^{2}$. In what follows, we hope to give a satisfactory answer to their main arguments. In different ways, both Hay and Finlayson argue that, in focusing on argumentation and deliberation, we misunderstand the nature of the political. Secondly, Finlayson thinks that there is a discontinuity between CDA, in its previous versions, and our present framework. Thirdly, Finlayson claims that CDA's focus on representations (on discourses) should not be displaced by a focus on action, that representations are fundamental in politics, that disagreement is fundamentally over premises, not over practical conclusions, and a rhetorical (not dialectical) perspective is best suited to analysing political discourse.

\section{The nature of the political}

Why is the political inherently connected to (practical) argumentation and deliberation, in our view? Let us briefly recapitulate our position. In Chapter 1 , we begin from a broadly Aristotelian conception of the political, in terms of deliberation on the common good, leading to decision and action. We also briefly survey various contemporary views formulated in terms of deliberation, decision-making, agency, action, resolution of conflict and disagreement by peaceful means, the public-private divide. It is not our intention to provide another definition of the political, but to enumerate what seems distinctive about it in various strands of political theory. Hay finds we are unduly privileging argumentation and deliberation among these strands. He argues that to 'reduce political discourse to practical argumentation' has three unfortunate consequences: it excludes political discourse which is not practical argumentation; it (presumably, artificially) reconstructs informal and non-elite political discourse as argumentative; finally, it leads to a naïve and idealized conception of democratic deliberation against which actual public deliberation is evaluated. For him, 'the political is about power' and to define it in terms of deliberation or argumentation, as we do, means to seriously 'narrow down' the domain of political discourse analysis. This narrow focus allegedly also makes us unable to see as political all those situations in which 'power is exercised without due deliberation'.

Let us emphasize from the start that we do not for a moment forget that the political is also about power and we devote a lot of space to definitions of power (by Lukes and Searle, Chapter 3 ) in relation to the political domain. Power, however, will remain a nebulous notion, of little analytical use, unless we can also show how it can be investigated in its discursive dimension, how it manifests itself 'in' (as well as 'behind') discourse.

Our approach draws to a large extent on dialectical theories of argumentation, which themselves often explicitly draw on linguistic pragmatics, i.e. on theories of verbal action (Searle 1969). Like pragma-dialectics (van Eemeren and Grootendorst 2004), we see argumentation as a verbal social activity (or a macro-speech act) with an illocutionary and a perlocutionary dimension: people do things by means of arguing, and this activity has effects. Our focus on practical reasoning, critical questioning and action is coherent with this overall pragmatic and dialectical view. We draw extensively on Searle's (2010) theory of the construction of the social world by means of speech acts, which is also to a large extent a theory of political power and of the specificity of the political. So,

\footnotetext{
${ }^{1}$ This article has been published in Political Studies Review 11 (3)/2013, pp. 336-344, DOI: 10.1111/14789302.12025.

${ }^{2}$ Fairclough, Isabela \& Fairclough, Norman (2012) Political Discourse Analysis. A method for Advanced Students, London: Routledge.
} 
starting from the Aristotelian conception on the nature of the political, defined in general terms in Chapter 1 , we gradually move (via Chapters 2 and 3 ) towards a view which is strongly influenced by Searle's conception of institutional reality and we draw on that view in the analytical chapters.

Some elements of Searle's conception of institutional reality are perhaps worth restating. For Searle (2010: 164), all political power is 'deontic power' and is therefore a matter of rights, obligations, duties, permissions, authorizations, prohibitions, and the like. These are conferred on individuals and objects in the processes whereby human beings create institutional reality. In the political domain, for example, becoming a citizen or an elected politician confers rights and obligations on individuals. All institutions enable and constrain human action, they create possibilities as well as restrictions on people's behaviour as agents operating within their constitutive rule-governed boundaries. The whole point of institutional reality is in fact to create and regulate power relationships between people: power flows through institutional reality via deontic powers collectively assigned and recognized. The essence of the political as a particular institutional domain is to be found (for Searle) in the system of deontic reasons that political institutions provide as (desire-independent) motives for action. Conflict or disagreement in politics can be over the distribution of social goods, but it can be also be over the (re)distribution of deontic powers, e.g. over who has the right to decide on matters of common concern. It is in this sense that we suggested seeing power as a reason, motivating action, enabling or constraining it.

At various points in the analytical chapters we focus on conflicts over perceived violations of existing commitments - the Liberal-Democrats' pre-electoral pledge not to increase tuition fees, or the current government's perceived failure to act in accordance with justice in failing to punish those responsible for the crisis. We show how such commitments are regarded as constitutive of the political institutions in question, of the implicit social contract with citizens. They are deontic reasons that political actors have, that ought therefore to motivate them. Political actors sometimes go to great lengths to show that they are in fact motivated by such reasons - for instance by a public commitment to fairness. Appealing to such reasons can be viewed as a manifestation of political power: the citizens' right to fair treatment and the government's obligation to act fairly are thus explicitly recognized as constraints on what the government can do. But deontic reasons can also be discussed in relation to power in another sense: the power to impose an argument (a policy) even when it is not a good argument (policy). Online commentators, in their capacity as citizens (Chapter 5), may avail themselves of their right to criticize government policy, but the fact that the force of the better argument is ignored by government and fails to lead to social change is also a manifestation of power. A similar point can be made about the debate on austerity (Chapter 4): extensive deliberation in various institutional settings across society has not led the government to change its position on austerity policies. This may not be because of some flaw in the quality of public debate but because the (possibly better) reasons emerging from that debate are being continuously overridden by reasons having to do with power, either political or economic power, or both.

Hay claims that 'whilst all situations of deliberation are political, not all political situations are deliberative' and cannot be therefore defined 'in terms of deliberation or practical argumentation'. We believe on the contrary that not all deliberative situations are political: people deliberate (either by themselves or together with others) on all sorts of non-political private issues. (This is to say that we do not extend the scope of the political as widely as Hay seems to do. For us, a private issue can become political, but only if the individual engages with it as a political actor, e.g. as a citizen in possession of rights, not as a private individual. By failing to relate the political to an institutional order, Hay deprives himself of a standard that would stop everything, and therefore nothing, from being political.) However, the political situations we analyze in the book do instantiate the genre of deliberation because, in all cases, argumentation is oriented towards the resolution of a difference of opinion about what to do, by means of critical testing of a practical claim, involving an attempt to think of reasons that would count against it. We agree none-the-less that not all political situations are deliberative, yet the ones that are non-deliberative in our view are not those to which Hay refers. There are examples of negotiation, adjudication or mediation in politics; like deliberation, these are argumentative in nature - there is no doubt about that. And there are other activities ('pre-genres', 'macro-speech acts') besides argumentation going on in political discourse namely narrative, description, explanation. We see them as generally subsumed or subordinated to 
argumentation, in the sense that, ultimately, they are supposed to give people reasons for what to believe and how to act. In a political context, a particular narrative or explanation about how the crisis came about would lose its pragmatic point or rationale unless it were connected ultimately with some conclusion about what it would be recommended to do. Finally, there are activity types in the political field that fall under Aristotle's class of epideictic (ceremonial) discourse - these are also non-deliberative but are fairly marginal and are outside the scope of our book.

These, however, are not the types of non-deliberative discourse that Hay seems to have in mind. For Hay, non-deliberative political situations are those in which 'power in exercised without due deliberation'. So obviously, for him, having (or pursuing) power is not a reason for action that enters in agents' reasoning processes, but somehow substitutes reasoning and deliberation. You can either 'duly' deliberate or pursue your power interests without deliberation. This is wrong, in our view. Throughout the book we try to develop a view of power as a reason or motive for action, a reason within deliberative processes, one which may often trump other reasons, but a reason none-theless. If an agent decides to ignore all the potential consequences that his proposed action might have on others and to act solely on grounds of actually having the political power to decide, or in order to further his own economic power interests, then, however minimally, that agent's action has been preceded by a deliberative process, in which some power-related concern has overridden other possible (maybe more legitimate) concerns. It may not be 'due' deliberation, but it is still deliberation. Both good and bad arguments are arguments, and deliberation that would fail all normative standards of evaluation is deliberation none-the-less. (A similar point is made in political theory by Elster - see page 30 in our book).

To sum up, we have no problem with the claim that power is often exercised without 'due deliberation'. This is what some of our analyses also illustrate: decisions for action taken by government after insufficient or inadequate deliberation, or by ignoring the force of the better arguments provided elsewhere. Power is of course often exercised without 'due deliberation', but it is not exercised without deliberation altogether. Simply, this is because to act within the political presupposes the existence of certain reasons for action, without which we could not speak about the political as an institutional order. Whatever other reasons an agent might have, the political provides him with a set of reasons that he has to take into account, one way or another, if only to disregard them. For us, to allow considerations that are extraneous to the political (say, economic ones) to prevail over, say, citizens' rights, in decision-making is also the outcome of a deliberative process, although quite possibly one that would not stand up to critical examination. To conclude, the political is a socially constructed institutional order. Its very fabric gives people reasons for action. To act within the political means having to take on board these reasons, whatever course of action one takes in the end, and whether one is eventually motivated by these deontic reasons or by other reasons.

On the whole, Hay seems to start from a reductive understanding of argumentation and deliberation. He does not seem to operate with the usual definition of argumentation, as an activity of giving and receiving reasons, of justifying and criticizing propositions. If he did, he would not claim that a focus on argument excludes from view private informal contexts: is argumentation not a pervasive and banal activity in everyday life, as well as in formal political contexts? As for those examples of formal, elite public political discourse that cannot allegedly be discussed as practical arguments ('normative argumentation, moral persuasion, ideological proselytizing, argument by assertion, folk demonization, name calling'), we would reply that some clearly can be discussed in terms of practical reasoning (ethics is after all concerned with what people ought to do; as for 'proselytizing', is it not a way of trying to persuade people to support a particular party or position by giving reasons why they should?) and some are frankly puzzling (how can an assertion be an argument? what exactly is 'folk demonization'?) and in need of clarification in order to see whether they are indeed non-argumentative. Similarly, for Hay, deliberation only seems to mean collective and possibly even democratic deliberation: an agent reasoning with others (maybe even in a formal democratic setting) and examining various alternative options. We do not use deliberation (just) in this very strong sense: to allow one's economic interest (or one's 'power interests') to prevail over one's duties, in deliberating with oneself only, is also a form of deliberation. 
Hay also criticizes the reconstruction of Guardian readers' on-line comments as practical argumentation, as opposed to analyzing them 'in their own (political) terms'. We are in no doubt that the material which we analyse is argumentative and deliberative. The on-line debate on bankers' bonuses is in fact a good example of the process of critical examination of an argument (the original argument in favour of tolerating inequality) by asking many of the possible critical questions that can be asked about such an argument (e.g. casting doubt on the acceptability of the premises, on the reasonableness of the conclusion given its actual consequences, etc.). In the process, the participants are giving reasons in favour of the opposite conclusion, thus constructing a counterargument. It is not only an example of argumentation (clearly seen here as 'critical discussion' or testing of a standpoint) but also one of collective deliberation, of weighing reasons in favour of a conclusion and its opposite so as to arrive at some normative judgment, albeit in a weakly institutionalized context, without clear temporal boundaries, and without the link to a collective decision and action that other formal deliberative contexts may afford. The rather puzzling view that argumentation and deliberation are absent from such informal political discourse can probably be explained in terms of their reductive understanding referred to above. The same applies to the claims that neither the pre-Budget speeches of Alistair Darling nor the speech of Tony Blair should be analysed and evaluated as cases of practical argumentation and deliberation. As we show in chapters 3 and 4, these arguments are explicitly formulated in terms of weighing reasons in favour and against various courses of action; moreover, the responses to these speeches in public and parliamentary debate do evaluate and criticize them in exactly these terms, as the outcomes of a process that was supposed to adequately test the proposed course of action but failed to do so. This indicates that such speeches are evaluated against a normative standard for deliberation, which may be idealized, in the sense that actual practice is often very different, but is hardly naïve.

Hay concludes that our approach 'takes us too far down the path to a narrowly deliberative and argumentative understanding of political discourse' and prevents the analyst from 'acknowledging the political moment in all discourse and the discursive moment in all politics'. This is an attractively symmetrical formulation, but what does it mean? For one thing, we think that Hay is wrong in identifying a political moment in all discourse, and we agree instead with Searle, who clearly links the political to the public sphere and to a particular institutional order. Secondly, speaking about the 'discursive moment in all politics' will not take us very far as analysts unless we are able to say something a bit less vague than the obvious fact that politics involves language or discourse. What exactly is the generic form of political discourse, what is its point as a form of human action and interaction, what is it oriented towards - these are more interesting and less obvious questions. And Hay's argument has not convinced us at all that political discourse is not argumentative, not deliberative, not oriented towards persuasion and, via this, towards (coordinating) action. Nor that such features are not useful in differentiating it from other types of discourse, e.g. from scientific inquiry or from literature.

We have addressed Hay's objection starting from Searle's view of the nature of the political. An alternative answer (along the lines we suggest in our section on legitimation in Chapter 3 ) would start by pointing out that the political can also be seen as the realm of public justification and of critical questioning of standpoints regarding matters of common concern. Argumentation is precisely the activity of justifying or criticizing standpoints. In a modern democratic state, policies that are proposed by government cannot be merely asserted, without giving reasons, i.e. without providing arguments; moreover, these reasons themselves have to withstand critical examination. We have no space to develop this line of argument here but its eventual convergence with the previous one should be obvious.

\section{PDA versus CDA?}

In our view, PDA contributes to CDA's objective of extending explanatory and normative critique to discourse, developing a synthesis of CDA and argumentation analysis. But Finlayson portrays it as abandoning the former for the latter, as abandoning 'critical neo-Marxist sociology' for 'liberal philosophical values', consequently as rejecting rather than building on CDA's insights into ideological representation. 
Finlayson usefully contextualizes PDA within controversies over the critique of political reason, yet does not engage with the treatment of argument evaluation at the heart of our approach, where critique of reasonableness is in fact clearly articulated with CDA-type critique. First, it is not just analysts that evaluate argumentation, but participants in deliberation as well. Our analytical object includes both practical argumentation and participant evaluation, and one consequence is that analysts evaluate evaluations. The analysts may come to the conclusion that a widely accepted line of argument does not withstand critical examination, yet seems to go unchallenged; or that an argument which is widely thought to be unreasonable is not rejected as such but allowed to inform policy. In both situations, questions of power, ideology, hegemony arise and can be clearly connected to questions of argument reasonableness. Second, the critical questions match the range of questions that participants can ask in principle, across diverse contexts of practical argumentation and practices of participant evaluation, but may not always ask. Why certain questions are asked and others are not can again be discussed in relation to CDA-type concerns with ideology and power. Third, in our view, standards of reasonableness hold for particular evaluative practices, they vary between practices and can be argued and fought over.

The possibilities for critical questioning can be viewed as a vehicle for social critique, as well as for normative evaluation of arguments; the two are clearly inter-connected. For example, participants (or analysts) can question whether the context of action is adequately represented, whether the arguer has provided an adequate understanding of what the 'problem' is (this may include adequate ways of defining, explaining, narrating how the situation came about). If the situation is not represented (described, defined, narrated, explained) adequately, if the representation cannot withstand criticism, one question for social critique would be why it is nevertheless being put forward as an adequate representation and whose interests are served by this. Similarly, the acceptability of goals and values can be challenged and in asking, for example, whether the arguer should have considered other goals or values, one is inevitably connecting with social critique - one is asking about other people's goals and values, and thus expanding the deliberative context beyond mere instrumentality. Finally, the same can be said about deontic reasons that are part of institutional orders: one can either inquire into why legitimate reasons are perhaps being overridden or one can attempt to open these reasons up for critique - the 'rules of the game' may themselves be indefensible. Normative analysis of arguments cannot help but naturally connect with social explanatory critique, and this is via a framework for deliberation-as-critical-questioning. This allows for critical questioning that expands the evaluation of any single argument by questioning each element of that argument and suggests the possibility of other premises, leading to other conclusions. These are increasingly 'critical' questions in a critical social analysis (and CDA) sense, probing for example into (structural) causes of circumstances and of representations of them, and advancing them can amount to 'practical critique'.

This way of looking at things provides a way of identifying different practices of evaluation in different contexts (e.g. parliamentary debates or Guardian readers' online comments), evaluating particular arguments against the standard of the relevant practice(s) and it makes available, to participants as well as analysts, a critique of a particular practice against standards which are external to that practice though not external to the social practices of the society in focus. If we relate this to Finlayson's account of critique in three 'traditions', it includes a Kantian concern with a standard of reasonableness against which arguments can be assessed but it also opens up a Wittgensteinian/Skinnerian concern with the contextual and historical nature of orders of reasonableness and also accommodates the concern of the third (Marxist) tradition with normative and explanatory critique and 'practical critique'.

Alan Finlayson tries to align our framework with one or another of the above traditions, but we are not ourselves explicitly or intentionally positioning ourselves within any of these. Our discussion of the constitutive deontology of the political may strike Finlayson as clearly 'neo-Kantian', but for us this is just one element of the overall picture. No doubt, desire-independent reasons for action are one category of reasons, both in politics and ordinary life, and practical conclusions can be evaluated as reasonable or not depending on how they take such reasons into account. It does not follow however that action is only reasonable if it is motivated by such reasons, or that external a priori standards of reasonableness should always be followed inflexibly, regardless of their consequences. On the contrary, we tend to emphasize how policies are more or less reasonable depending on the 
actual consequences or effects they produce, on how they endeavour to take these into account and how they manage to balance a concern for several possibly conflicting non-overridable concerns. If our approach may seem eclectic, this is also because practical reasoning operates with eclectic reasons: duties, commitments, desires, interests, consequences, moral-political values, and the like. So we would resist any attempt at labelling our approach as 'Kantian' or whatever. One further area in which we do not see fundamental incompatibilities is between traditional CDA concerns for equality and justice and neo-Aristotelian conceptions of 'human flourishing'; such syntheses can in our view be productive in the work of social scientists (e.g. Sayer 2011).

\section{Action versus representation, rhetoric versus dialectic}

Both Alan Finlayson and Colin Hay criticize PDA for focusing on action at the expense, as they see it, of representation. While the focus of the book is indeed on practical argumentation and action, we refer to extensive treatments of representation in earlier CDA not to dismiss them, but to strengthen their critical relevance, by showing that representations are best analysed as elements of forms of action, or genres, be they argumentative, explanatory, narrative.

Hay notes that analysts who emphasize the causal/constitutive role of discourses and ideas are better at capturing 'the political as distinct from the discursive dimension of their analytical foci'. The fact that he makes this point as a criticism of PDA shows that he misses a crucial point: much discussion of the causal/constitutive effects of discourses and ideas has nothing to say about how they can have such effects, whereas in our account discourses ('ideas') can give people reasons for favouring one line of action over others and thereby have effects on decisions to act (and lead to changes in the world). We are therefore not abandoning the social critique of CDA, but seeking to strengthen it. We do not reject CDA's insights into ideological representation in favour of normative evaluation of arguments, but try to accommodate both within our model of evaluation.

According to Alan Finlayson, claims of the form 'we should do x' are not a focus of political disputes; the latter 'take place not at the level of conclusions but at that of premises', over ways of representing the situation. In other words, the issue is not 'what is to be done?' but 'what is going on? If one can persuade the public that 'the crisis you face is a crisis of government spending, the solution is, in broad outline clear': it follows 'naturally' from the definition of the situation.

In our view, political disputes can be over representations in premises as well as over practical conclusions of arguments. First, as we show in our discussion of persuasive definitions (including metaphorical definitions) as premises of arguments (pp. 92-95, 170-172, etc.), their use is rhetorically motivated and can be effective because certain claims for action follow more persuasively from certain representations of the context of action than from others. If the country's economy is for example analogous with that of a domestic household, then putting an end to borrowing can be more easily defended. It may be therefore rhetorically effective for a politician to represent the country's economy as a household economy, but there will always be dialectical constraints on that particular way of representing reality (e.g. how good is in fact this analogy or redefinition?). In other words, even when a particular audience has been persuaded, how rationally persuasive is the argument from a normative perspective? The same can be said of Finlayson's own example, which involves an implicit explanation. (To say that the crisis is one of government spending is to say that it was caused by government spending.) Again, this representation may be effective rhetorically, but possibly dialectically questionable, as the underlying explanation may be questionable. But casting doubt on the way the situation or circumstances are defined, explained or narrated, if it is the case that these circumstances function as premises in a subsequent argument for action, will cast doubt on the conclusion that is drawn on the basis of these representations. So the political dispute is transferred from the premises to the conclusion, and (in our view) this is precisely because the point of defining, explaining or narrating events is to figure out (or make a proposal about) what to do, based on first figuring out what the situation is (or at least trying to accredit a view of it). To see the dispute as occurring only at the level of the premises would be to occlude what the ultimate rationale or point of politics is as a rational goal-oriented human activity, which (we think) is not to arrive at some representation of the situation as an end in itself, but in view of drawing some practical-normative conclusion, in view of doing something about it. We also 
disagree that, once there is agreement on representations, the conclusion follows naturally. No practical conclusion really follows from the premises: practical arguments are typically plausible and presumptive in nature, not deductively valid, if only for the reason that there is always some 'known' or 'unknown unknown' that can defeat the move from premises to conclusion.

Finlayson also claims that representations and action should not be separated (as we allegedly do), that representations are actions. There is a sense in which we would not dispute that: the sense in which assertions, directives and other types of speech acts are all speech acts, or the sense in which we can speak about the performative power of all language: one can institute the reality of a promise but also the reality of a new way of representing reality. But we would not like to miss one important difference between these two situations: various types of speech acts (as Searle first observed) have different directions of fit. Ultimately, a promise or a directive aims to make the world match the words that were spoken (world-to-word direction of fit), while a representative (assertive) speech acts aims to correspond to the world (or has a word-to-world direction of fit) and expresses a commitment to truth (note that this is different from saying it is true) - hence the dialectical constraints on any representation or assertion: is it an acceptable (accurate, true) representation of the situation? In other words, not just any kind of reality is a man-made linguistic construct, and an assertion is an 'action' in a different sense than a promise. We think the distinction between representations and actions should be preserved, that doing so is consistent with a general theory of human intentionality in which beliefs about the world (i.e. 'representations' of states of affairs, together with desires, needs, etc.) are reasons for action, and that no useful analytical purpose is served by confusing them. In our view, one strength of our framework is that it accommodates those aspects of political discourse which are important in Finlayson's view (ideological representations, political disputes which centre upon representations) without however reducing political discourse to them. On the contrary, it shows how beliefs and representations connect with action, via practical reasoning, or how (in our own formulation) structures (e.g. discourses, including ideological representations) connect with agency by providing agents with reasons for action.

Our differences may result from a different way of understanding the relationship between rhetoric and dialectic. While we draw primarily on dialectical theories of argumentation, Finlayson privileges the rhetorical perspective and seems to connect the political domain with rhetoric only. The existence of a third-party audience is supposedly the crucial ingredient here: a political actor's goal is often not to persuade his opponent (as this may be highly unlikely anyway) but to win the debate in the eyes of a third-party audience, and to do so he will need to root his arguments in premises that will resonate with that audience. All this is true, of course, but we see no reason to abandon pragma-dialectics' own way of acknowledging an arguer's double (dialectical and rhetorical) goal. Nor do we think that politics is not the realm of dialectics but only of rhetoric. As our analyses show, arguments in favour of policy $\mathrm{X}$ or $\mathrm{Y}$ may be rooted in beliefs and values that the audience has or can be made to accept, but are also designed to withstand real or anticipated critical questioning from that audience, an audience that 'talks back', in a process of extended public dialogue, against a background of controversy. For us, it is not possible to say of a political speech (e.g. the Blair example) that it is 'rhetoric' only, and cannot be discussed as an example of deliberation or from a dialectical point of view. We take the view that logic, rhetoric and dialectic are three possible perspectives on any argument, and an argument can be rhetorically strong but dialectically and logically weak (the case of fallacies) or vice-versa.

\section{Conclusion}

We hope to have answered the most important arguments made by Hay and Finlayson. There are of course many areas where our framework needs further development and we are addressing some in current work (e.g. developing our concept of strategy, systematizing critical questions into dialectical profiles, exploring the 'problematization' of situations).

Naturally, we focus in our book on developing our own particular method, not on applying other analysts' methods. We do refer however to other methods in discourse analysis and in argumentation theory, and also indicate how other theoretical frameworks (e.g. the cognitive 
theories of metaphor or framing) can be productively articulated with our approach. Hay suggests nevertheless that we are promoting a form of 'methodological absolutism'. In response, we admit that we do make a strong case for focusing on practical argument but we do so against the background of (what we see as) the rather astonishing neglect of it in political discourse analysis and its centrality in politics. One pleasing suggestion in both Finlayson's and Hay's responses is that by setting out our stall strongly, clearly and maybe provocatively, we might be a catalyst for a much needed interdisciplinary debate on methodology in the field of political discourse analysis.

References

Eemeren, F. H. van and Grootendorst, R. (2004) A Systematic Theory of Argumentation. The pragma-dialectical approach, Cambridge: Cambridge University Press.

Sayer, A. (2011) Why Things Matter to People: Social Science, Values and Ethical Life, Cambridge: Cambridge University Press.

Searle, J.R. (1969) Speech Acts, Cambridge: Cambridge University Press.

Searle, J. R. (2010) Making the Social World. The Structure of Human Civilization, Oxford: Oxford University Press. 